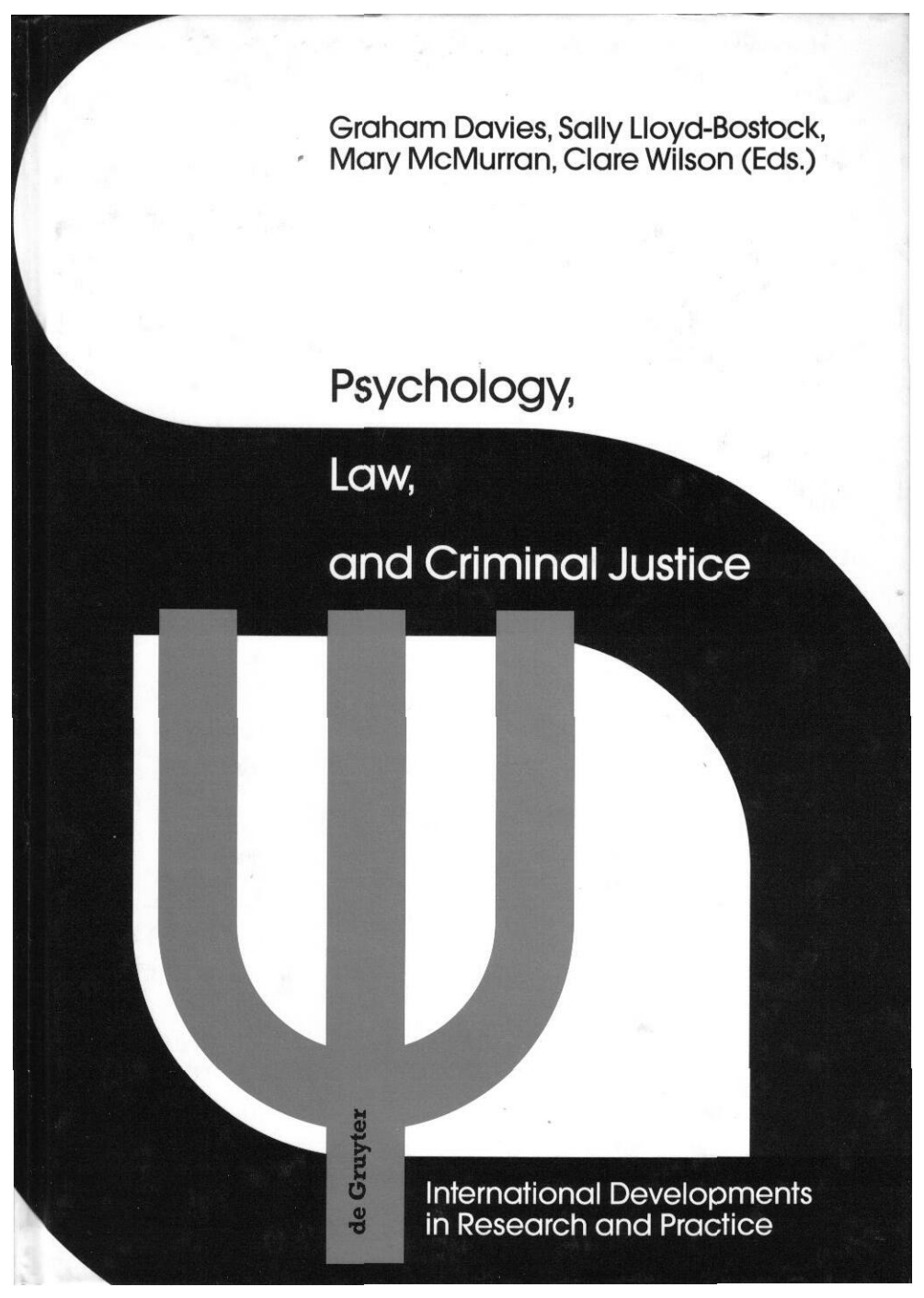

Manzanero, A.L. y Diges, M. (1995): Effects of preparation on internal and external memories. En G.DAVIES, S.M.A LLOYD-BOSTOCK, M.

McMURRAN y C.WILSON (Eds.): Psychology, law and criminal justice. International developments in research and practice. Berlín: W. De Gruyter \& Co. Pág. 56-63.

ISBN: 3110138581 


\section{Effects of Preparation on Internal and External Memories $^{1}$}

\section{Antonio L. Manzanero and Margarita Diges}

Johnson and Raye (1981) proposed a model based on the distinctive qualities of representations of internal and external memories and on the reasoning process which occurs in reality monitoring. According to this model, the information about memory representations are coded neither automatically nor directly in the precise moment when they are formed. They postulated the existence of four types of essential features through which people might differentiate between internal and external representations. External memories hold more contextual and sensorial features and more semantic details, while self-generated memories exhibit more information about cognitive operations. This Johnson and Raye (1981) theory has been supported by more recent studies (e.g. Johnson et al., 1984, 1988; Suengas \& Johnson, 1988) which have also manipulated variables such as delay. The process which people use to discriminate the two kinds of memories depends on several factors. Johnson and Raye (1981) emphasise that it does not always follow the same pattern and that it will vary according to the memory information, the conditions at encoding and the costs of error.

Several experiments suggest the existence of characteristic features for different types of memory. For example, there are studies which have found differential features for external memories in comparison to self-generated events such as dreams (Johnson, Kahan, \& Raye, 1984) or imagery (e.g. Johnson, 1988; Johnson, Foley, Suengas, \& Raye, 1988; Johnson, Raye, Wang, \& Taylor, 1979; Suengas \& Johnson, 1988).

In this way, Johnson and Raye (1981) distinguished three categories of selfgenerated information: (a) re-representations of perceptual experience or memories about something previously experienced; (b) co-temporal thinkings, elaborative and associative processes which connect or enhance the on-going perceptual experience but which are not necessarily part of the original representation; (c) fantasies, which combine new information with imagined events. We could add three more categories of self-generated information: (1) that generated by misleading information; (2) selfsuggested information on the basis of previous knowledge; and (3) lies.

The above-mentioned studies can be considered as an attempt to examine the discrimination processes between internal and external memories; their main aim has been to study the process that people follow to differentiate between their own memories. On the other hand, there are studies which have tried to examine the characteristic features of several types of memory information (Schooler et al., 1986, 1988; Alonso-Quecuty, 1992). These studies have used the differential features proposed by Johnson et al. in their model, and their main aim has been to examine how different types of memory information are affected by different yariables. The aims are not the only thing in which these studies differ. Johnson et al. $(1984,1988)$ used daily live material, autobiographic memories from dreams and imaginings with the 
analysis based mainly on asking for the evaluation of the subject's own recall and application of discrimination rules. Schooler et al. (1986, 1988) analyzed the descriptions made by subjects about a single object. And Diges (1992) as well as Alonso-Quecuty (1992) studied each individual statement as a whole.

Schooler, Gerhard and Loftus (1986) used the Reality Monitoring Model to try to establish the characteristic features of really perceived objects and of the descriptions of not perceived but suggested objects. In their study, slides were shown to people depicting a traffic accident in a crossroad where there was a yield sign. A misled group saw the same series of slides but with a yield sign substituted for a stop sign. Afterwards, the misled group read questions which implied that the stop sign was a yield sign. The descriptions made by the misled subjects who admitted the suggested information as real were compared with the descriptions given by the real-information subjects. Schooler et al. (1986) identified a series of features which differentiated the two: descriptions of suggested memories were significantly longer and had more verbal hedges, more references to cognitive operations and less sensorial details than reality-originated descriptions.

Later, Schooler, Clark and Loftus (1988) carried out a second study which changed the material (three stolen objects replaced the yield sign) and the modality of recall (oral instead of written recall). The results showed that the suggested memories had more references to cognitive processes, more self-references (the pronoun "T" appeared more frequently) and more verbal hedges, whereas in the real memories there were more allusions to perceptive processes and more sensorial details. However, there were no differences in the length of descriptions of internally generated narratives compared to external memories.

Alonso-Quecuty (1992) has tried to differentiate between real memory and lies using the features proposed by Johnson and Raye (1981). For this purpose, she used as material a film of an incident. After the film, half of the subjects were asked to report the event lying in such a way that the aggressor was exculpated and later they had to report what really happened. The other half of the subjects were first asked for the real story and secondly for the false one. She also manipulated a second variable: time to prepare their reports (immediate or delayed). The descriptions of the lies contained more internal characteristics than the descriptions of the true stories, but only when subjects were asked to recall or lie immediately. Delayed true statements contained more internally generated, while delayed false statements contained more external characteristics, except for idiosyncratic information (what the subjects thought and felt during the event). In this latter case, the false statements contained less idiosyncratic information than the true statements.

Finally, Diges (1992) has studied the effect of previous knowledge or belief about typical events on the coding and retrieval of information about a witnessed event. In this study, subjects holding extreme masculine or feminine sex driver stereotypes were told that the driver in a filmed traffic accident was a man or a woman, and afterwards were asked to recall the event. Results showed that priming an extreme category or schema can improve immediate free recall, but any advantage disappeared with a delay of six weeks. Further, the delay increased the number of distortions or incorrect details reported consistent with the driver stereotypes. Memories based on 
extreme schemata showed the attributes of internally originated memories (Johnson \& Raye, 1981) or suggested memories (Schooler et al., 1986) on immediate but not on delayed recall.

As can be seen, researchers have explored how several factors may influence attributes and discrimination processes in both internal and external memories. It has been observed that several variables have opposing effects on characteristic attributes for each of the two memory types, for example a lie and a real memory (AlonsoQuecuty, 1992).

Suengas (1991) points out five variables which influence reality monitoring processes: age, subject matter, delay, thinking or talking about memory contents, perceptive resemblance and the reduction in cognitive mechanisms.

Delay and, of course, thinking or talking about eyewitnessed events are major factors. As described by Alonso-Quecuty (1992), delay caused internal memories (those obtained by lies) to be intermingled, reducing differentiation from external memories, because subjects generate a very rich representation which could lead to reality characteristics appearing more often in lies.

Suengas and Johnson (1988) found that the most durable aspect of memory representations were contextual information; while the most degradable was idiosyncratic information. On the basis of these results, Suengas (1991) argued that the only source of errors between perceived and imagined events is idiosyncratic information: if we do not influence the process, delay produced better discriminations about the memory sources (Suengas, 1991). That could seem to be in disagreement with Alonso-Quecuty's results (1992). However, we must take into consideration the other variable mentioned by Suengas: thinking and talking about the events. Suengas (1991) affirmed that delay is useful because time exaggerates the differential characteristics of internally and externally originated information. She also argued that thinking about an event affects real and imagined memories in very different ways. If the event has emotive connotations, then thinking and talking about it will increase internal characteristics of the events. Because of that, discrimination will be more difficult. The emotive characteristics are among the most important aspects of a witnessed event. Thus, thinking and/or talking about an event reduce reality characteristics. To keep eyewitnesses from talking or thinking about an experienced event is very difficult, if not impossible.

In summary, the reality monitoring process involves discriminating among several memory sources. There are two general memory sources: perception and selfgeneration. Both types of descriptions of memory information have been found to differ in terms of the length of the narrative, the amount of sensorial and contextual details, the mentioning of cognitive processes and in general idiosyncratic information. Several studies have showed that these characteristics vary over time.

Therefore, it could be interesting to explore the effect of preparation on the characteristics of "internal" (imagined) and "external" (real) memories. Following recent research (Alonso-Quecuty, 1992; Suengas \& Johnson, 1988) it was hypothesized that real memories of subjects in the preparation condition would contain more sensorial and contextual details and more internal characteristics - in terms of the Johnson and Raye (1981) reality monitoring - than subjects in the 
spontaneouş condition. Also, statements of subjects asked to prepare a report of an imagined event should contain more external characteristics than the imagined memories of subjects who do not receive instructions about preparing their statements.

\section{Method}

\section{Design and subjects}

Two variables were of interest, the origin of the memory (perceived vs. imagined) and the preparation of reports (prepared vs. spontaneous), both manipulated as betweensubjects factors. The subjects were 64 male and female undergraduate students from the University Autónoma of Madrid. Subjects were assigned at random to the four groups. Accuracy measures (sensorial and contextual details, distortions, impossible information and inventions), and qualitative variables associated with internal characteristics (explanations, length of the narrative, changes in the narrative order, mentioning of cognitive processes and hesitant expressions) were drawn from the free recall descriptions.

\section{Materials and procedure}

Half of the subjects were asked to remember a filmed traffic accident ( 27 seconds duration) shown on a video screen. The rest of the subjects were presented with an oral description of the accident and were asked to imagine it. Then half of each group were asked to recall immediately what they had seen or imagined, and the remainder were asked to prepare written reports.

Following a procedure used in previous work (Diges, 1988, Diges et al., 1992) the statements were typed and analyzed by two independent trained judges in terms of the presence or absence of the quantitative and qualitative variables. Later, they evaluated the whole statements. Final scores were assigned by agreement.

\section{Results and Discussion}

The analyses (ANOVA) showed that imagined declarations, compared with reality declarations, exhibited more sensorial and contextual details, $F(1,60)=164.782$, $\mathrm{p}<.0001$; more distortions, $\mathrm{F}(1,60)=4.034$, $\mathrm{p}<.05$; more "impossible information", $\mathrm{F}(1,60)=4.369, \mathrm{p}<.05$, and were longer, $\mathrm{F}(1,60)=20.233$, $\mathrm{p}<.001$. Also, they had less explanations, $\mathrm{F}(1,60)=4.722, \mathrm{p}<.05$ and less hesitant expressions $\mathrm{F}(1,60)=6.691$, $\mathrm{p}<.01$. In other words, the imagined statements unexpectedly showed more external characteristics than the reality statements.

Spontaneous compared with prepared reports exhibit less sensorial and contextual details $\mathrm{F}(1,60)=5.36, \mathrm{p}<.05$; and less hesitant expressions $\mathrm{F}(1,60)=5.874, \mathrm{p}<.01$. The interaction effects of origin of memory $x$ preparation of reports on hesitant expressions was also significant, $\mathrm{F}(1,60)=5,874, \mathrm{p}<.01$. 
Because of these results are partially in disagreement with our predictions and with previous results, we explored further. Imagined reports had more sensorial and contextual details, associated to external memories. A check of the procedure showed that these results were due to the "imagine" instructions. It produced that the imagined narratives had more details than normal. Subjects under the reality condition had few opportunities to perceive all the details showed in the film. In the reality condition, events occurred quickly and, furthermore, subjects had to process several details simultaneously. Meanwhile, the "imagine" subjects were provided with a sequential description of the event, so they had more opportunities to process details.

Because of this, we considered it interesting to analyze separately the preparation effect on internal memories and on external ones. Moreover, by taking into consideration the results of other authors (Alonso-Quecuty, 1992; Suengas \& Johnson, 1988) we hypothesized that preparation would produce an internalisation of the reality memories and an externalisation of imagined memories. Thus, each variable was analyzed independently in the internal and external groups. Results are presented first for the external memories and then for internal ones.

\section{Externalmemtories}

A t-test was computed on accuracy and qualitative scores. The effect of preparation on sensorial and contextual details $(t(28)=1.618 ; \mathrm{p}<.05)$ and on hesitant expressions $(t(28)=2.687 ; \mathrm{p}<.01)$ was significant in both cases. Thus, external prepared declarations had more hesitant expressions $(M=1.2)$ than external spontaneous declarations $(M=0.267)$.

We also observed that with preparation there were more sensorial and contextual details ( $M=12.8 ; M=10.8$ respectively). These results could be due to the preparation process which consists not only in information organisation, but also in a higher effort to recall, both of which could lead to greater remembering.

These results are in accordance with the findings of Alonso-Quecuty (1992) who found that delayed narratives had more sensorial and contextual information and more idiosyncratic features. Also, our results coincide with the ones by Suengas and Johnson (1988) who found that delay produced that real narratives had the same amount of contextual information but modified idiosyncratic characteristics. They observed that thinking and talking about the stored information produced higher idiosyncratic scores when subjective and affective connotations were the main characteristics.

In summary, when previously experienced information is prepared, recall will exhibit more internal characteristics (idiosyncratic information) and greater amounts of detail than in the spontaneous conditions. In other words, preparation causes external declarations to become more internal.

\section{Internal memories}

A t-test was computed on accuracy and qualitative scores. The effect of preparation on sensorial and contextual details $(t(32)=1.867 ; \mathrm{p}<.05)$ and explanations $(t(32)=1.680$; $\mathrm{p}<.05$ ) was significant. 
Prepared imagined narratives had less idiosyncratic information, in the sense that there were less explanations $(M=1.118)$ than in the spontaneous descriptions $(M=2.294)$. Thus, the imagined memories lost their internal characteristics. And also, subjects under the prepared conditions recalled more details $(M=31.588)$ than in the spontaneous condition $(M=27.235)$, as happened in the real memory case, and because of the same reasons.

These results fit those of Alonso-Quecuty's (1992). She too found that delayed false declarations had less idiosyncratic information and more sensorial and contextual details than immediates. Thus, preparation causes internal narratives to become more external.

\section{General Discussion}

The Reality Monitoring Model (Johnson \& Raye, 1981) was applied to the study of the effects of preparation on internal and external memories. Statements accuracy and idiosyncratic variables were assessed, given that their theory identifies these as the main variables to discriminate between internal and external memories.

The results showed that in the preparation condition, when subjects were asked to prepare their narratives about something previously experienced, the statements contained more internal characteristics than when subjects spoke spontaneously. On the other hand, the statements were more external when subjects were asked to prepare their declarations about an event previously imagined.

How could we explain this preparation effect on internal and external memories? It seems that in the reality condition, subjects perceive, code and store selected information about the events. When subjects were asked to prepare their memory statements, they recalled the memory traces and rebuilt the information. When it is time to talk about the event, they speak not about the perceived event but about the interpreted, coded reorganised, stored, recalled and rebuilt event. This is recall about a memory "trace" (perhaps, defined as a re-representation in terms of Johnson and Raye, 1981).

In the case of imagined events the process was very similar. Here the recall concerns an internally experienced event. When the imagined memory statement is tested in the preparation condition we have recall based upon a memory trace.

Every time we recall an event, internally or externally experienced, memory traces become more and more labile. Moreover, if during this time we prepare, talk or/and think about the event, these internal and external characteristics will be more and more affected. External memories become more internal, and internal memories become more external. When real memory statements are prepared there is a greater involvement of cognitive processes, which produces internalisation of the traces. In the case of imagination, preparation mainly produces an enrichment of the scene; in other words, more sensorial and contextual details and more coherence, and softer idiosyncratic characteristics which produce recall with more external characteristics than with immediate recall.

As the real or the imagined trace is more temporally distanced from the original it becomes more difficult to differentiate the source, because of trace impairment. 
Subjects must reconstruct the scene and integrate all the suggested and self-suggested information (misleading information, lies, self-suggestions from previous knowledge, or imagination).

Our results lead us to think that the characteristic features proposed by the reality monitoring model (Johnson \& Raye, 1981) might not be invariably applied to Statements Reality Analysis. For example, the statements of witnesses about an incident are analyzed after a considerable delay and victims and eyewitnesses report the events on many occasions. Both aspects imply that the reality characteristics would diminish. Moreover, some techniques of reality analysis (e.g. Steller, 1988) propose as a good method to guide the witnesses' recall the cognitive interview (Geiselman, 1988; Memon et al., 1990, 1991). This procedure produces more and more preparation of the statements, and because of that, it could provoke greater amounts of information but with fewer reality characteristics. Because of this risk, the main task should be to ensure that eyewitnesses' statements are analyzed as soon as possible. Delay is not the only difficulty for the analysis, additional time spent on report preparation could make the analysis impossible.

Finally, the increase of hesitant expressions in the real descriptions have an important implication about credibility. Although confidence do not correlate with accuracy (Wells \& Murray, 1984), jurors base their credibility evaluations on the eyewitness confidence (Wells, Lindsay, \& Ferguson, 1979). The greater amounts of doubt probably affect the eyewitness credibility.

In summary, preparation affects in a very important way the statements' accuracy in the case of eyewitnesses. It causes more detailed reports for both internal and external memories, but also it reduces statements' qualities. The first effect was already known, and we should also take note of the second.

\section{References}

Alonso-Quecuty, M. L. (1992). Deception detection and reality monitoring: A new answer to an old question? In F. Lösel, D. Bender, \& T. Bliesener (Eds.), Psychology and law. International perspectives (pp. 328-332). Berlin: W. de Gruyter.

Diges, M. (1988, July). The accuracy/credibility relationship is free recall of a filmed traffic accident. Poster presented at NATO Advanced Institute on Credibility Assessment, Maratea, Italy.

Diges, M. (1992, September). Previous knowledge and delay in the recall of filmed events. Paper presented at the Third European Conference on Law and Psychology, Oxford, England.

Diges, M., Rubio, M. E., \& Rodriguez, C. (1992). Eyewitness memary and time of day. In F. Lösel, D. Bender, \& T. Bliesener (Eds.), Psychology and law. International perspectives (pp. 317. 320). Berlin: W. de Gruyter.

Geiselman, R. E. (1988). Improving eyewitness memory through mental reinstatement of context. In G. M. Davies \& D. M. Thomson (Eds.). Memory in context: Context in memory. New York: Wiley \& Sons.

Johnson, M. K. (1988). Reality monitoring: An experimental phenomenological approach. Journal of Experimental Psychology: General, 117(4), 390-394.

Johnson, M. K., Foley, M. A. Suengas, A. G., \& Raye, C. L. (1988), Phenomenal characteristics of memories for perceived and imagined autobiographical events. Joumal of Experimental Psychology: General, 117(4), 371-376. 
Johnson, M. K., Kahan, T. L., \& Raye, C. L. (1984). Dreams and reality monitoring. Journal of Experimental Psychology: General, 113(3), 329-344.

Johnson, M. K, \& Raye, C. L. (1981). Reality monitoring. Psychological Review, 88(1), 67-85.

Johnson, M. K., Raye, C. L., Wang, A. Y., \& Taylor, T. H. (1979). Fact and fantasy: The roles of accuracy and variability in confusing imaginations with perceptual experiences. Journal of Experimental Psychology: Human, Learning and Memory, 5(3), 229-240.

Memon, A., \& Bull, R. (1990, September). The cognitive interview: Its origins, empirical support, evaluation and practical implication. Paper presented at Second European Conference on Law and Psychology, Nürnberg. Germany.

Memon, A., \& Bull, R. (1991, June). La entrevista cognitiva: Cómo y por qué puede mejorar la memoria de un testigo. I Encuentro Hispano-Británico de Psicología Jurídica, Pamplona.

Schooler, J. W., Clark, L. A., \& Loftus, E. F. (1988). Knowing when memory is real. In M. M. Gruneberg, P. E. Morris, \& R. N. Sykes (Eds.), Practical aspects of memory: Current research and issues. New York: Wiley.

Schooler, J. W., Gerhard, D., \& Loftus, E. F. (1986). Qualities of the unreal. Journal of Experimental Psychology: Learning, Memory, and Cognition, 12(2), 171-181.

Steller, M. (1988). Recent developments in statement analysis. In J. C. Yuille (Ed.), Credibility assessment. The Netherlands: Kluwer Academic Publishers.

Suengas, A. G. (1991). El origen de los recuerdos. In J.M. Ruiz-Vargas (Ed.), Psicología de la memoria. Madrid: Alianza.

Suengas, A. G., \& Johnson, M. K. (1988). Qualitative effects of rehearsal on memories for perceived and imagined complex events. Journal of Experimental Psychology: General. $117(4), 377$ 389.

Wells, G. L. Lindsay, R. C. L., \& Ferguson, T. J. (1979). Accuracy, confidence, and juror perceptions in eyewitness identification. Journal of Applied Psychology, 64(4), 440-448.

Wells, G. L. \& Murray, D. N. (1984). Eyewitness confidence. In G. L. Wells \& E. Loftus (Eds.), Eyewitness testimony. Psychological perspectives. New York: Cambridge University Press.

We are grateful to the pupils of Facultad de Psicología in Universidad Autónoma de Madrid. We are also grateful to Carmen Gentil for her help with the statement analysis, and to Clare Wilson and Miguel Muñoz for their help with the translation. This research was supported by grants from the Comunidad Autónoma of Madrid FPI $n^{\circ}$ C242/91 to A. L. Manzanero, and from DGICYT PB890170 to M. Diges. 